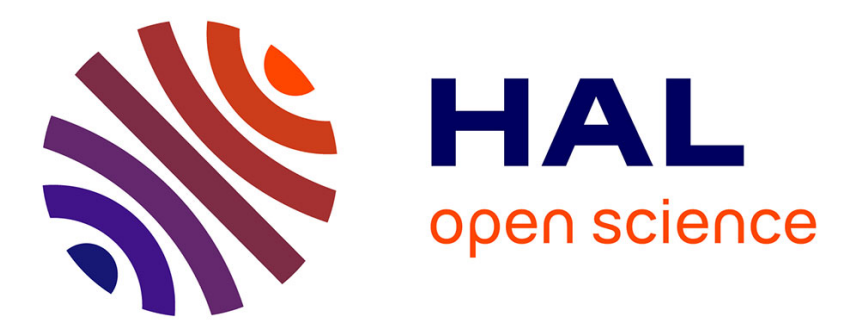

\title{
Seismo-ionosphere detection by underground SQUID in low-noise environment in LSBB-Rustrel, France
}

G. Waysand, Pierre Barroy, R. Blancon, Stéphane Gaffet, C. Guilpin, J.

Marfaing, E. Pozzo Di Borgo, M. Pyée, M. Auguste, D. Boyer, et al.

\section{- To cite this version:}

G. Waysand, Pierre Barroy, R. Blancon, Stéphane Gaffet, C. Guilpin, et al.. Seismo-ionosphere detection by underground SQUID in low-noise environment in LSBB-Rustrel, France. European Physical Journal: Applied Physics, 2009, 47 (1), pp.12705. 10.1051/epjap:2008186 . hal-00480181

\section{HAL Id: hal-00480181 https://hal.science/hal-00480181}

Submitted on 3 May 2010

HAL is a multi-disciplinary open access archive for the deposit and dissemination of scientific research documents, whether they are published or not. The documents may come from teaching and research institutions in France or abroad, or from public or private research centers.
L'archive ouverte pluridisciplinaire HAL, est destinée au dépôt et à la diffusion de documents scientifiques de niveau recherche, publiés ou non, émanant des établissements d'enseignement et de recherche français ou étrangers, des laboratoires publics ou privés. 


\title{
Seismo-Ionosphere Detection by Underground SQUID in Low-Noise Environment in LSBB - Rustrel, France
}

\author{
Georges Waysand $^{1}$; Pierre Barroy ${ }^{2}$; Rémi Blancon ${ }^{3}$; Stéphane Gaffet ${ }^{4}$ Christian Guilpin ${ }^{5}$; Jannie Marfaing ${ }^{6}$; Elisabeth \\ Pozzo di Borgo ${ }^{3}$; Maurice Pyée $;$ Michel Auguste ${ }^{1}$; Daniel Boyer ${ }^{1}$; Alain Cavaillou ${ }^{1}$ \\ ${ }^{1}$ Université de Nice Sophia-Antipolis, Laboratoire Souterrain Bas Bruit de Rustrel-Pays d'Apt (LSBB), La Grande Combe F- \\ 84400 Rustrel georges.waysand@oca.eu \\ ${ }^{2}$ Université Paris XIII, LPMTM, Institut Galilée, F-93430 Villetaneuse \\ ${ }^{3}$ Université d'Avignon et des Pays de Vaucluse, Département de Physique, rue Louis Pasteur F-84000 Avignon \\ ${ }^{4}$ Université de Nice Sophia-Antipolis, GéoSciences-Azur, 250 rue Albert Einstein F-06500 Sophia-Antipolis \\ ${ }^{5}$ Université Paris7-Denis Diderot, 2 Place Jussieu F-75005 Paris \\ ${ }^{6}$ Universites Aix-Marseille IM2NP- UMR 6242 CNRS-, Faculte des Sciences et Techniques, \\ Avenue Normandie Niemen F - 13397 Marseille Cedex 20 \\ ${ }^{7}$ Université d'Orléans, LPCE CNRS, 3A av. de la Recherche Scientifique F-45071 Orléans
}

\begin{abstract}
The permanent operation of a 3 axes SQUID magnetometer in the LSBB below 550m of calcite rock is a unique system of magnetic observation: a rejection rate better than $3 \mathrm{fT} / \sqrt{\mathrm{Hz}}$ over $40 \mathrm{~Hz}$. The observation of magneto-ionosphere responses to $\mathrm{P}$ wave emissions both at the epicentre and at their arrival at LSBB for earthquakes of magnitude larger than 3 is reported. A simple model predicts the starting time of these events. These results are compared with those provided by Doppler sounders for ionosphere responses to Rayleigh waves.
\end{abstract}

PACS. 91.10.Vr Ocean/Earth/atmosphere/ hydrosphere/cryosphere interactions; mass balance - 94.20.Bb Wave propagation 85.25.Dq Superconducting quantum interference devices (SQUIDs)

\section{Introduction}

The conversion of the former launching control room $n^{\circ} 1$ of the nuclear missile launching system of Albion Plateau into an underground laboratory enabled the achievement of a unique setup for the observation of terrestrial magnetism. In a naturally low-noise environment it is a 3 axes low- $\mathrm{T}_{c}$ SQUID (Superconducting QUantum Interferometer Device) magnetometer located inside an exceptional electromagnetic shielding acting as a low-pass filter: the former launching control room, buried 550m underground, as described in $\$ 2$. As shown in $\S 3$, this instrument records damped ultra low frequency wave trains whose maximum amplitude may reach several hundreds of picoTesla. They are generated by ionosphere vertical excitations. Their amplitude is comparable to earth magnetic fluctuations at the beginning and the end of a solar partial eclipse. The $\mathrm{P}$ wave propagation in the atmosphere above the seism epicentre and at its arrival at Rustrel accounts for the triggering time of these damped ionosphere excitations. These events are different from the one detected by the ionosphere sounders $(\$ 4)$. Beyond 2000 $\mathrm{Km}$ away from Rustrel, the first magneto-ionosphere response to the seism is detected before ground $\mathrm{P}$ wave at the LSBB.

\section{The LSBB permanent magnetic observatory}

A very low-noise seismic and electromagnetic environment, plus an exceptional shielding without $\mu$ metal or superconducting screens allows the permanent operation of a SQUID magnetometer for the observation of earth magnetic field.

\subsection{A naturally low-noise environment}

For seismic excitations of periods over 5 seconds, acceleration spectrum at LSBB, with an accuracy of $10 \mathrm{~dB}$, is close to the world theoretical minimum, placing the LSBB among the best sites for seismic calm on Earth. Moreover, the electromagnetic noise spectrum exhibits a monotone decrease versus frequency from a maximum at the entry of LSBB of $2 \times 10^{5} \mathrm{fT} / \sqrt{ } \mathrm{Hz}$ at $0.5 \mathrm{~Hz}$. The low value of that maximum expresses the electromagnetic calm at the ground level, the monotone decrease the absence of near-by noise sources. Under $550 \mathrm{~m}$ of limestone, the noise level at $0.5 \mathrm{~Hz}$ is reduced to $10^{3} \mathrm{fT} / \sqrt{\mathrm{Hz}}$; in addition, above $600 \mathrm{~Hz}$ the noise level reaches the SQUID intrinsic noise level $3 \mathrm{fT} / \sqrt{ } \mathrm{Hz}$.

\subsection{The LSBB capsule: a unique shielding}

The last factor of electromagnetic noise reduction is a cylindershaped horizontal capsule, $28 \mathrm{~m}$ long and $8 \mathrm{~m}$ diameter, $14 \mathrm{~mm}$ thick of semi-mild steel, enclosed in a shell of reinforced concrete around $2 \mathrm{~m}$ thick. The magnetometer is in a sand box on a $100 \mathrm{~m}^{2}$ floor suspended by springs and shock absorbers at the centre of the capsule. Bronze-beryllium leaf-springs ensure the continuity of electromagnetic shielding when access door is closed. Thus over $40 \mathrm{~Hz}$ the intrinsic noise level of SQUID is reached. It is not a zero gauss chamber since no $\mu$-metal shields DC field. This system is not strictly a-magnetic (Waysand \& al. 2000) [1]. As a whole it is an unparalleled low-pass filter, which enabled the first detection of the magneto-hydro-seismic response, synchronous with the arrival into the karstic system of Vaucluse plateau of $\mathrm{P}$ wave generated by a magnitude 6.1 quake 
in India, $6250 \mathrm{~km}$ far from Rustrel, (Gaffet et al. 2003) [2]. These signals were in the order of magnitude of tens of picoTesla.

\section{Detection of ionosphere excitations}

These exceptional conditions motivated the installation of a permanent 3-axes low- $T_{c}$ SQUID magnetometer from StarCryo ${ }^{\circledR}$ inside the capsule. The combination of a SQUID inside this Shielding Qualified for Ionosphere Detection is what we call the Rustrel [SQUID] $]^{2}$ system. In addition, a 3D array of seismometers: four in the tunnel and a fifth at the surface on top of the Grande Montagne towering the laboratory and the [SQUID] ${ }^{2}$ magnetometer within the capsule, continuously monitor the low-noise. Identical data acquisition stations for [SQUID] $^{2}$ and the seismometers allow direct comparison between seismic and magnetic signals.

\subsection{Uncorrelated magnetic signals with local seismic activity}

Data acquired by $[\text { SQUID }]^{2}$ encompass a great variety of phenomena. The most frequent appear at very low frequencies as shown on the recording of a typical quiet evening: whereas the signal of reference seismometer clearly indicates the arrival of only one earthquake, the SQUID records several damped magnetic oscillation trains with large amplitude and long period just before the seismometer seismic signal. Figure 1 displays the simultaneous recording on three components (EW, NS and vertical) of reference seismometer and SQUID magnetometer, both filtered between 0.01 and $10 \mathrm{~Hz}$, on the $2^{\text {nd }}$ of January 2006 between 9 and $12 \mathrm{pm}$. As shown on this figure, magnetic oscillations can be observed even in the absence of any earthquake but could also be seen when the seismometer simultaneously detects the arrival of seismic waves. Thus those oscillations are not signals generated within Earth's crust.

\subsection{Signals coming from the ionosphere}

Figure 2 represents an enlargement of a part of magnetic variations alone measured by the SQUID around $22 \mathrm{~h}$ on January $2^{\text {nd }} 2006$. Not only the signal of the $\mathrm{Z}$ component (upper trace) is much smaller than the NS (central trace) and EW one (lower trace) but, the $\mathrm{Z}$ component relative variations are far smaller than for NS and EW. This indicates that a vertical displacement of charges provokes the magnetic oscillations. The amplitude of NS and EW signals is of the order of a fraction of nanoTesla, therefore far greater than hydro-magneto-seismic signals. Slow variations of such amplitude were observed at the occasion of the partial solar eclipse by the Moon on march $29^{\text {th }}, 2006$ (figure 3). This is in good agreement with the idea that those signals are really produced in the ionosphere. Their occurrence may be computed.

\subsection{The excitation mechanism: atmospheric $P$ waves propagation up to the ionosphere floor.}

In spite of bad acoustic coupling, an earthquake puts into vibration the air column above its epicentre. The simplest supposable excitation is the one emitted at the arrival of the $\mathrm{P}$ wave. The ionosphere floor being at $90 \mathrm{Km}$ of altitude, it is reasonable to estimate at 300 seconds the propagation time of the wave until its encounters charged particles. For a deep earthquake this duration is increased by the time necessary for the wave to go up to the surface at $6 \mathrm{Km} / \mathrm{s}$. When the ground $\mathrm{P}$ wave arrives at Rustrel, if this site is not in the shadow cone, a second emission occurs. For the evening of January $2^{\text {nd }} 2006$ and all the earthquakes over magnitude 3 , the obtained results are represented on figure 4 . In 12 instances out of 13 the remarkable fitting between the computed time and the starting time for the magnetic oscillation validates this interpretation. (The 13th instance corresponds to an electromagnetic emission concomitant with a seism of magnitude 7.1, a phenomenon observed from time to time, even for low-magnitude earthquakes). It should be noted that all these earthquakes occurred in very different locations all over the globe (Table 1).

\section{Comparison with ionosphere soundings and conclusion}

Radar ionosphere sounders operate in the $\mathrm{MHz}$ range and need therefore the existence of a Doppler effect on a reflecting layer at the scale of their wavelength, which occurs near $150 \mathrm{Km}$ of altitude. Moreover, they are only sensitive to Rayleigh waves arriving at the sounding site since they induce surface oscillations far stronger than $\mathrm{P}$ waves. [SQUID] $]^{2}$ system because of its lownoise environment responds to $\mathrm{P}$ waves emitted at the epicentre and when they arrive at Rustrel.

The excitations triggered by these waves refer thus to a density of charged particles much lower than that existing at $150 \mathrm{~km}$. The fact that the ascension time to the ionosphere is the same whatever the earthquake location, seems to indicate the absence of night-day effect for a layer so lightly ionised but detectable by SQUID in low-noise environment thanks to collective charge oscillation.

For earthquakes occurring at a distance over about $2000 \mathrm{Km}$ from Rustrel, the first ionosphere response is then a precursor of the arrival of the $\mathrm{P}$ wave at Rustrel. The periods of signals are of several tens of second.

At these wavelengths the device is always close to source point, that is why it detects the ionosphere responses wherever the earthquake occurs. Its sensitivity allows, with an appropriate filtering the observation of the resonance frequencies of the ionosphere layer explored by the sounders between 200 and 300 seconds (Lognonné 2006) [3]. This device is clearly a powerful complement for ionosphere studies.

\section{Acknowledgements}

We want to thank Jean François Méla and Roger Maynard, who made possible the creation of this permanent installation when they had responsibilities in the Ministère de l'Éducation Nationale as well as François Lefeuvre, Michel Parrot (both from LPCE Orléans) and Jean Matricon (Paris7 Denis Diderot) for fruitful discussions. This work was also made possible by fundings within the Plan Pluri-Formation for LSBB from Ministère de l'Éducation Nationale et de la Recherche. 


\section{References}

1 Waysand, D.Bloyet, J.P.Bongiraud, J.I.Collar, C.Dolabdjian, $\mathrm{Ph}$ Le Tiec. Nuclear Instruments and Methods A444 336 (2000).

2 S. Gaffet, Y.Guglielmi, J. Virieux, G. Waysand, A. Chwala, R. Stolz, Ch.Emblanch, M.Auguste, D.Boyer, and A.Cavaillou. J. Int. (2003) 155, 981-990G.

3 Ph. Lognoné, R.Garcia, F. Crespon, G.Ochipinti,A.Kherani, J.Artru-Lambin. Europhysics News 37, 11 (2007) 


\section{Figures and table captions}

Figure 1. Three components (EW, NS and Z vertical) simultaneous time recording of reference seismometer and [SQUID] ${ }^{2}$ system on January $2^{\text {nd }} 2006$ between 21 and $24 \mathrm{~h}$ (9 and 12pm). Several damped magnetic oscillation trains (the three upper traces) are occurring during a perfect seismic calm period interrupted at $22 \mathrm{~h} 32$ by the arrival of PKP waves from a Southeast of Fiji Islands earthquake( $M=7.2)$ (the three lower traces).

Figure 2. Detail of signals recorded by the [SQUID] ${ }^{2}$ signals between $21 \mathrm{~h} 40$ and $22 \mathrm{~h} 30$ on 2006.01 .02 . Vertical solid lines indicate earthquake triggering times (and magnitude) during this period.

Figure 3. Magnetic field components as registered by [SQUID]2 during the partial solar eclipse by the Moon on march 29th 2006. The three white arrows indicate the beginning of the eclipse on the Earth, its maximum and the end of the occultation. The two black arrows show the beginning and the end of the eclipse in Rustrel. The variations of magnetic field are in every case in the order of magnitude of a fraction of nanoTesla. The plateau on EW is due to instrument saturation.

Figure 4. Ionosphere responses of $\mathrm{P}$-waves for earthquakes $\mathrm{M}>3$. Earthquake triggering times are indicated by solid lines. $\mathrm{P}$ waves arrival times at the ionosphere floor vertically above the epicenter are indicated by black arrows; $\mathrm{P}$ waves arrival times a the ionosphere floor above Rustrel (dot lines) are indicated by the white arrows. 12 out of 13 wave trains are well described as atmospheric $\mathrm{P}$ waves exciting the ionosphere. Earthquakes locations are listed in Table 1.

Table 1. Time, magnitude and location of Earthquakes indicated in fig.4 
Figures and tables
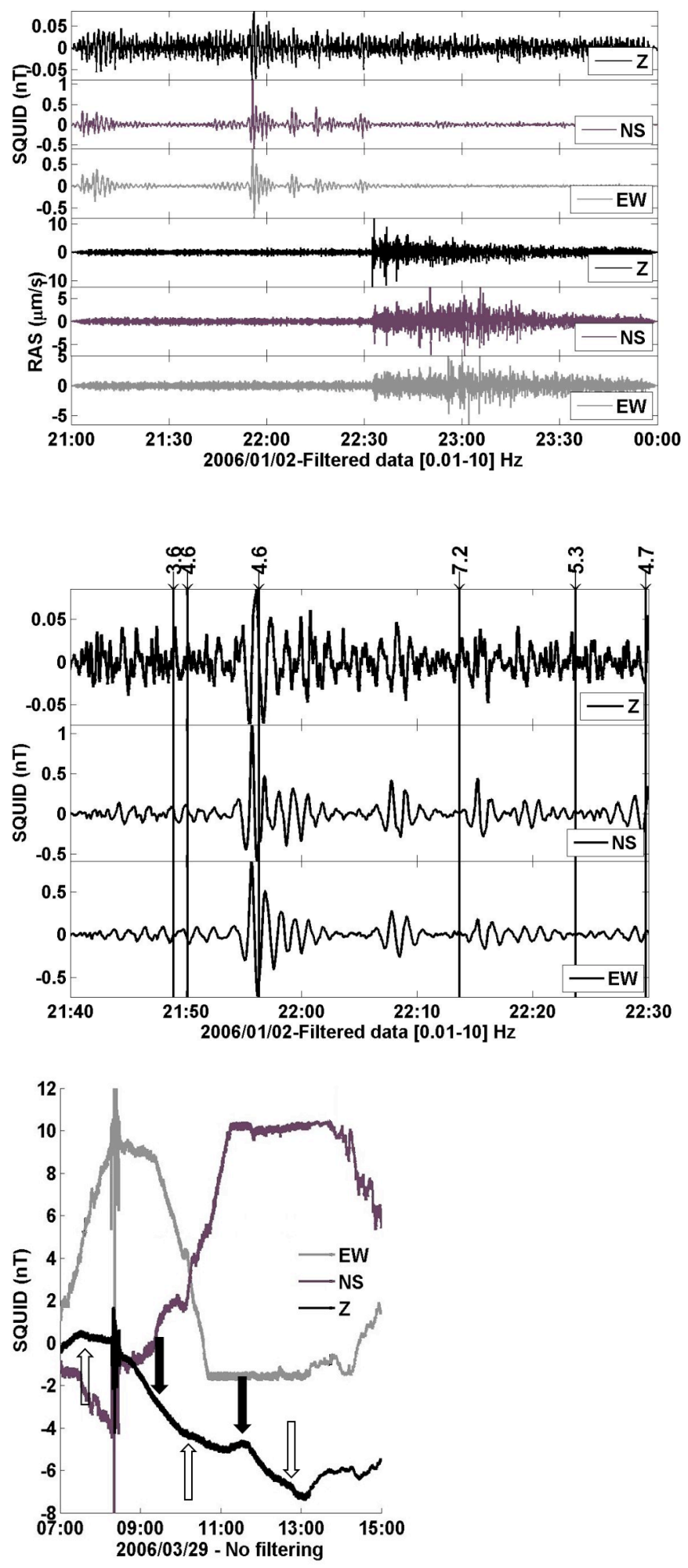


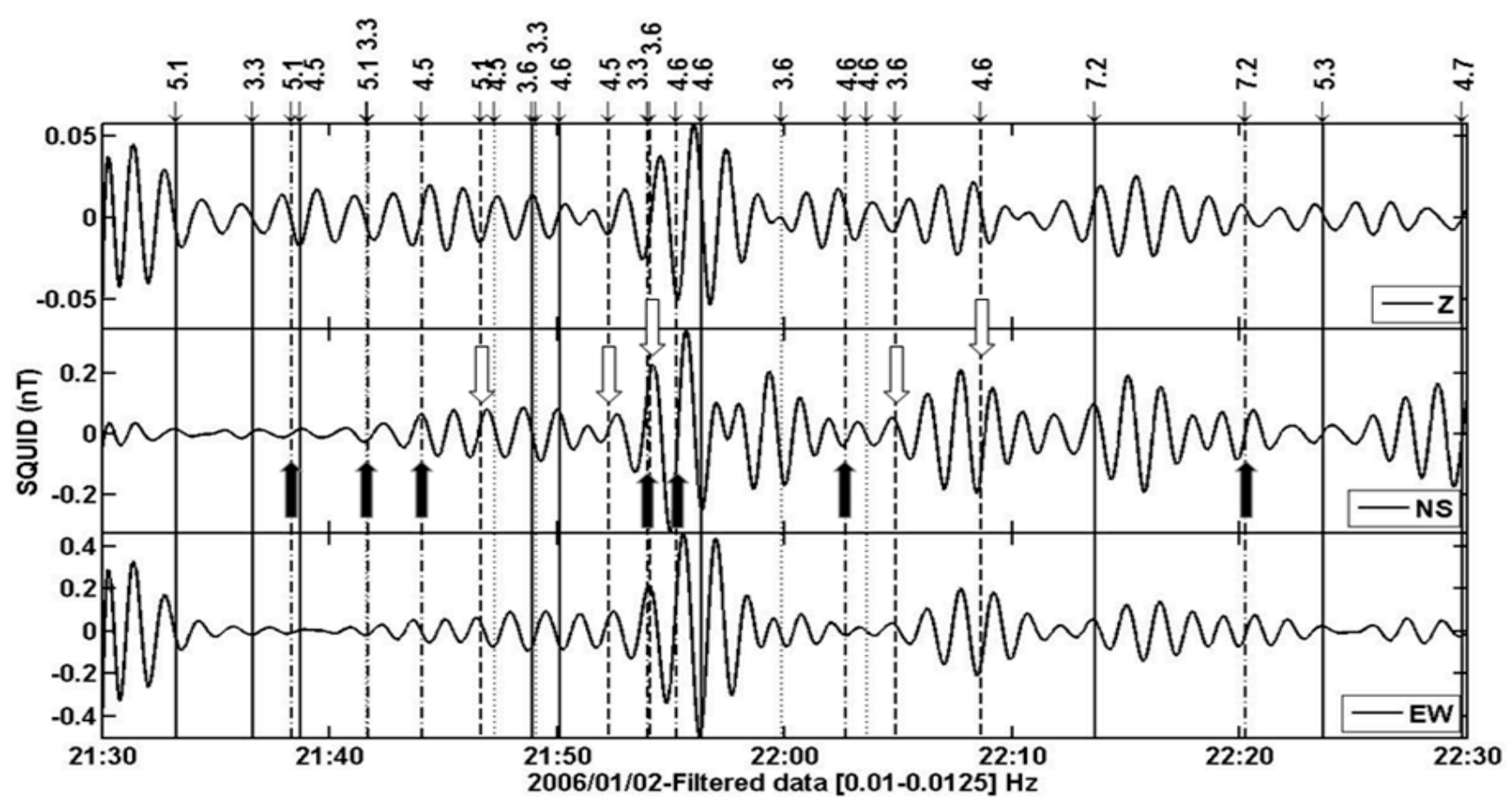

\begin{tabular}{|l|l|l|}
\hline $\begin{array}{l}\text { Triggering } \\
\text { time }\end{array}$ & Mag. & Location \\
\hline $21: 33: 18$ & 5.1 & $\begin{array}{l}\text { NORTHERN MID-ATLANTIC } \\
\text { RIDGE }\end{array}$ \\
\hline $21: 36: 39$ & 3.3 & UNIMAK ISLAND REGION \\
\hline $21: 38: 44$ & 4.5 & AFGHANISTAN \\
\hline $21: 48: 56$ & 3.6 & SOUTHERN ILLINOIS \\
\hline $21: 50: 08$ & 4.6 & SOUTH OF HONSHU, JAPAN \\
\hline $21: 56: 21$ & 4.6 & $\begin{array}{l}\text { KERMADEC ISLANDS } \\
\text { REGION }\end{array}$ \\
\hline $22: 13: 40$ & 7.2 & FIJI ISLANDS REGION \\
\hline $22: 23: 41$ & 5.3 & FIJI ISLANDS REGION \\
\hline $22: 24: 31$ & 4.4 & FIJI ISLANDS REGION \\
\hline $22: 29: 47$ & 4.7 & FIJI ISLANDS REGION \\
\hline
\end{tabular}

